\title{
MENINGKATKAN KETERAMPILAN BERBICARA DENGAN MENGGUNAKAN MODEL PEMBELAJARAN KOOPERATIF TIPE STAD SISWA KELAS X IIS 5 SMA NEGERI 2 BANJARMASIN
}

\author{
M. Ridha Anwari, Akhmad Syakir, Muhammad Yunus \\ Program Studi Pendidikan Bahasa dan Sastra Indonesia \\ FKIP, Universitas Muhammadiyah Banjarmasin \\ Jl. S. Parman Komplek Rumah Sakit Islam, Kode Pos 70114, \\ e-mail Ridhaanwariyahoo.co.id
}

\begin{abstract}
Abstrak
Penelitian yang berjudul "Meningkatkan Keterampilan Berbicara dengan Menggunakan Model Pembelajaran Kooperatif Tipe STAD Siswa Kelas X Iis 5 SMA Negeri 2 Banjarmasin" ini bertujuan untuk memperoleh data dan mendeskripsikan peningkatan keterampilan berbicara siswa kelas X-1 SMA Negeri 2 Banjarmasin dengan menggunakan model pembelajaran tipe STAD dan untuk mengetahui dan mendeskripsikan aktivitas siswa dan guru saat mengunakan model pembelajaran kooperatif tipe STAD pada materi keterampilan berbicara.

Dengan adanya penelitian ini diharapkan dapat memberikan manfaat sebagai pedoman untuk dapat lebih meningkatkan lagi kemampuan berbicara siswa kelas X IIS 5 SMA Negeri 2 Banjarmasin yang pada akhirnya turut meningkatkan hasil belajar siswa.

Penelitian ini dilaksanakan di kelas X IIS 5 SMA Negeri 2 Banjarmasin pada semester pertama tahun ajaran 2017/2018, yaitu dari bulan Juli hingga Desember 2017. Populasi dalam penelitian ini adalah siswa kelas X IIS 5 SMA Negeri 2 Banjarmasin dengan sampel sebanyak 33 orang.

Metode yang digunakan dalam penelitian ini adalah metode deskriptif melalui penelitian tindakan kelas dengan mengambil tempat penelitian di Kelas X IIS 5 SMA Negeri 2 Banjarmasin. Teknik pengumpulan data yang digunakan adalah menggunakan hasil tes awal dan tes akhir kegiatan setiap siklus, dan hasil observasi terhadap aktivitas siswa dan guru selama pembelajaran berlangsung, serta angket untuk mengetahui respon siswa terhadap pembelajaran kooperatif tipe STAD.

Indikator penilaian dalam penelitian mencakup aspek keterampilan berbicara, aktivitas siswa, dan aktivitas guru.

Berdasarkan hasil penelitian, ditinjau dari semua aspek menunjukkan bahwa: (1) Pembelajaran kooperatif tipe STAD dapat meningkatkan keterampilan berbicara siswa dari rata-rata 66,6 dengan ketuntasan klasikal $60 \%$ pada siklus I meningkat menjadi rata-rata 80,1 dengan ketuntasan klasikal 97\% pada siklus II. Hasil kerja kelompok semua mendapat penghargaan super, (2) Aktivitas siswa mengalami peningkatan dari $69 \%$ pada siklus I mengalami peningkatan menjadi 89\% pada siklus II, dan (3) Aktivitas guru mengalami peningkatan dari rata-rata 2,6 dengan kategori baik menjadi rata-rata 3,7 dengan kategori baik pada siklus II.

Disarankan agar guru bahasa Indonesia khususnya di kelas X IIS 5 SMA 2 Banjarmasin dapat menggunakan model pembelajaran kooperatif tipe STAD ini, karena dapat meningkatkan minat siswa dalam pembelajaran bahasa Indonesia serta memotivasi siswa dalam belajar dan pada akhirnya berdampak pada peningkatan hasil belajarnya.
\end{abstract}

Kata Kunci: Model Pembelajaran, Kooperatif, Tipe STAD. 


\begin{abstract}
Abstrack
This research aims to gather the data and to describe Grade X students' improvement in their speaking skill after using STAD Cooperative Learning. It is also intended to describe the students and the teacher's activities in the classroom.

This research is expected to be able to give a clear picture on how to improve students' speaking skill, which eventually will affect their learning achievement.

The present research was conducted by inviting second semester students of Grade X IIS (Social Science Program) 5 SMA Negeri 2 Banjarmasin in academic year 2017/2018, started from July to December 2017. The population of this research was all students, with 33 students as the samples.

It employed descriptive research method by using classroom action research design. The research setting was in the Class X of IIS (Social Science Program) 5 SMA Negeri 2 Banjarmasin. In every cycle, the result of pre- and post-test was used to gather data about students' achievement. In addition, observation and questionnaire was also utilized to better understand students' responses on the use of STAD cooperative learning.

The indicators used in this research covered several aspects, including students' speaking skill, students' activities, and teacher's activities.

Based on findings, it was found that: (1) the use of STAD cooperative learning was able to improve students' speaking skill, indicated by their progress from 66.6 average score with $60 \%$ of classical completeness in cycle I to 80.1 average score with $97 \%$ of classical completeness in cycle II. Their group work got outstanding reward, (2) the students' activities improved from $69 \%$ in cycle I became $89 \%$ in cycle II, and (3) the teacher's activities improved from 2.6 in average with good category to 3.7 in average with good category in cycle II.

It is suggested that Bahasa Indonesia Teachers, especially in Grade X of IIS 5 SMA N 2 Banjarmasin to implement STAD cooperative learning because it can improve students learning interest as well as encourage them in learning, which finally affected their learning outcome.
\end{abstract}

Keywords: Learning Model, Cooperative Learning, Type STAD

\title{
Pendahuluan
}

Ruang lingkup mata pelajaran bahasa Indonesia mencakup kemampuan berbahasa dan bersastra yang meliputi empat aspek yaitu berbicara, mendengarkan, membaca dan menulis. Dari empat aspek tersebut, keterampilan berbicara merupakan salah satu keterampilan berbahasa yang sangat penting karena keterampilan berbicara merupakan salah satu keterampilan berupa mengemukakan pendapat secara lisan tanpa mengabaikan tiga aspek lainnya yaitu berbicara, membaca dan mendengarkan.

Manusia dalam kehidupannya membutuhkan informasi secara langsung dari lingkungannya secara lisan. Hal ini diperlukan adanya keterampilan berbicara yang baik.begitu pula siswa dalam proses pembelajaran dituntut memiliki kemampuan dalam mengkomunikasikan informasi yang diterimanya. 
Menciptakan siswa yang memiliki keterampilan dalam berbicara harus dilakukan bagi semua siswa. Dengan demikian dalam proses pembelajaran guru dapat menggunakan model pembelajaran kooperatif. Salah satunya adalah model pembelajaran kooperatif tipe STAD.

Berdasarkan hasil wawancara dengan guru pengajar bahasa Indonesia di SMA Negeri 2 Banjarmasin bahwa hasil belajar siswa pada mata pelajaran bahasa Indonesia berada pada ketuntasan 53\%, dimana siswa yang tuntas hanya 18 orang dari 33 siswa. Penyebab rendahnya hasil belajar siswa disebabkan, karena materi pelajaran diajarkan secara konvensional, siswa bersifat pasif meskipun pembelajaran dengan sistemk-13 mulai diupayakan. Data hasil wawancara dengan guru pengajar bahasa Indonesia bahwa kemampuan berbicara siswa masih rendah. Dengan demikian perlu adanya latihan-latihan agar keterampilan berbicara siswa dapat meningkat.

Bila hal tersebut dibiarkan akan berdampak pada menurunnya prestasi belajar siswa, dan siswa akan menganggap pelajaran bahasa Indonesia adalah pelajaran yang membosankan, dan sulit, karena bersifat hafalan. Untuk mengatasinya perlu dicarikan alternatif model pembelajaran yang tepat, yang membuat siswa lebih termotivasi dalam belajarnya. Oleh karena itu perlu diujicobakan model pembelajaran kooperatif tipe STAD pada mata pelajaran bahasa Indonesia.

Alasan menggunakan model STAD adalah karena berdasarkan hasil penelitian Lundgren (Ibrahim, 2000 : 17) menunjukkan bahwa pembelajaran kooperatif tipe STAD memiliki dampak yang amat positif untuk siswa yang rendah hasil belajarnya.

Berdasarkan uraian di atas maka penulis tertarik untuk mengadakan penelitian dengan judul Meningkatkan Keterampilan Berbicara dengan Menggunakan Model Pembelajaran Kooperatif Tipe STAD Siswa Kelas X IIS 5 SMA Negeri 2 Banjarmasin.

\section{Kajian Pustaka}

Berbicara adalah suatu keterampilan berbahasa yang berkembang pada kehidupan anak, yang didahului oleh keterampilan menyimak, dan pada masa tersebutlah kemampuan berbicara atau berujar dipelajari (Tarigan, 2008: 3).

Menurut Tarigan (2008:16) berbicara adalah kemampuan mengucapkan bunyi-bunyian artikulasi atau kata-kata untuk mengekspresikan, menyatakan atau menyampaikan pikiran, gagasan, dan perasaan.

Tarigan (2008: 4) juga menyatakan berbicara dan menyimak merupakan kegiatan-kegiatan komunikasi dua arah yang langsung, merupakan komunikasi tatap muka.

Keterampilan berbicara berhubungan erat dengan tiga keterampilan lainnya dengan cara beraneka ragam. Dalam memperoleh keterampilan berbahasa, biasanya kita melalui suatu hubungan urutan yang teratur: mula-mula pada masa kecil kitamenyimak bahasa, kemudian berbicara, sesudah itu kita membaca (Tarigan, 2008: 1). 
Sebagai makhluk sosial manusia memerlukan suatu keterampilan berbicara agar bisa berkomunikasi dengan baik terhadap orang lain. Namun kemampuan berbicara seseorang memerlukan latihan yang serius, agar setiap orang memiliki keterampilan berbicara yang baik.

Kemampuan siswa dalam keterampilan berbicara masih rendah, hal ini terlihat dari banyaknya siswa yang pasif pada saat kegiatan diskusi dilaksanakan dalam pembelajaran bahasa Indonesia. Oleh karena itu, keterampilan berbicara sudah menjadi target para guru untuk meningkatkannya.

Peningkatan kemampuan berbicara seseorang tergantung pada tingkat latihan yang dilakukan siswa. Dengan demikian untuk meningkatkan kemampuan berbicara, khususnya di depan kelas, dan juga di depan umum perlu adanya pelatihan yang terencana dengan baik bagi guru pengajar bahasa Indonesia di sekolah.

Peningkatan kemampuan berbicara pada proses pembelajaran bahasa Indonesia dapat dilakukan melalui penggunaan metode diskusi kelompok, metode demonstrasi, metode Role Playing (bermain peran), metode debat secara formal, dan metode lainnya yang dapat melatih para siswa dalam kemampuan berbicaranya.

Pembelajaran model STAD dalam pembelajarannnya mengacu pada belajar kelompok siswa, menyajikan informasi akademik baru kepada siswa menggunakan presentasi verbal atau teks. Siswa dibagi dalam beberapa kelompok heterogen dengan 5-6 orang tiap kelompok. Anggota tim menggunakan lembar kegiatan atau perangkat pembelajaran yang lain untuk memahami bahan pelajaran melalui tutorial, kuis, satu sama lain dan atau diskusi secara individu setiap minggu atau setiap dua minggu siswa diberi kuis dan diskor, perkembangan didasarkan pada jumlah skor yang melampaui rata-rata skor siswa yang lalu. Setiap minggu diumumkan tim-tim dengan skor tertinggi (Ibrahim dan Nur, 2000:55)

\section{Rumusan Masalah}

Berdasarkan latar belakang di atas, maka dapat dirumuskan masalah yang akan diteliti sebagai berikut :

1. Apakah terdapat peningkatan hasil belajar siswa pada keterampilan berbicara siswa Kelas X IIS 5 SMA Negeri 2 Banjarmasin dengan menggunakan model pembelajaran kooperatif tipe STAD?

2. Apakah terjadi peningkatan aktivitas siswa dengan menggunakan model pembelajaran kooperatif tipe STAD pada materi keterampilan berbicara?

3. Apakah terjadi peningkatan aktivitas guru dengan menggunakan model pembelajaran kooperatif tipe STAD pada materi keterampilan berbicara? 
Tujuan Penelitian

Berdasarkan permasalahan di atas tujuan penelitian dirumuskan berikut ini:

1. Peningkatan hasil belajar keterampilan berbicara siswa Kelas X IIS 5 SMA Negeri 2 Banjarmasin dengan menggunakan model pembelajaran kooperatif tipe STAD

2. Aktivitas siswa dengan menggunakan model pembelajaran kooperatif tipe STAD pada materi keterampilan berbicara.

3. Aktivitas guru dengan menggunakan model pembelajaran kooperatif tipe STAD pada materi keterampilan berbicara.

\section{Metode Penelitian}

Penelitian ini dilaksanakan dengan menggunakan rancangan Penelitian Tindakan Kelas (PTK). Penelitian tindakan kelas ini menekankan kepada kegiatan (tindakan) dengan mengujicobakan suatu ide ke dalam praktek atau situasi nyata dalam skala mikro, yang diharapkan kegiatan tersebut mampu memberbaiki dan meningkatkan kualitas proses belajar mengajar.

Penelitian ini dilakukan dalam 2 siklus dan setiap siklus terdiri dari dua kali pertemuan. Diharapkan dalam 2 siklus pembelajaran, keterampilan siswa kelas X IIS 5 SMA Negeri 2 Banjarmasin dalam penguasaanl materi keterampilan berbicara dapat ditingkatkan.

Menurut Arikunto (2008:74) setiap siklus pada penelitian tindakan terdiri dari tahapantahapan, yaitu: (1) perencanaan (planning), (2) pelaksanaan tindakan (acting), (3) pengamatan (observasi), (4) refleksi (reflecting).

\section{Hasil dan Pembahasan}

1. Hasil Belajar Siswa dengan menggunakan model pembelajaran kooperatif tipe STAD

Dari hasil pembahasan data nilai yang diperoleh pada kegiatan siklus I dan siklus II dapat diuraikan perbandingan hasil belajar siswa sebagai berikut:

Tabel 4.9 Perbandingan Hasil Belajar Siklus I dan Siklus II

\begin{tabular}{|c|c|c|c|c|c|c|c|c|c|c|c|c|c|c|c|c|c|c|c|c|}
\hline K & $\mathrm{e}$ & $\mathrm{g}$ & $\mathrm{i}$ & $\mathrm{a}$ & $\mathrm{t}$ & $\mathrm{a}$ & $\mathrm{n}$ & $S$ & $\mathrm{i}$ & $\mathrm{k}$ & 1 & $\mathrm{u}$ & $\mathrm{s}$ & I & S & $\mathrm{i} \quad \mathrm{k}$ & 1 & $\mathrm{u}$ & s & I I I \\
\hline $\mathrm{T}$ & $\mathrm{e}$ & $\mathrm{s}$ & & $\mathrm{a}$ & w & $\mathrm{a}$ & 1 & 3 & & 2 & & & & 7 & 2 & & 8 & & . & 6 \\
\hline $\mathrm{T}$ & e & $\mathrm{s}$ & & A & $h$ & $\mathrm{i}$ & $\mathrm{r}$ & 6 & & 7 & & & & 6 & 8 & & 0 & & . & 1 \\
\hline & $\mathrm{tu}$ & $\mathrm{nta}$ & $\mathrm{sal}$ & $\mathrm{n} 1$ & 1 & & & 7 & & & & & & 5 & 9 & & & & & 5 \\
\hline
\end{tabular}

Berdasarkan pengolahan nilai hasil belajar siswa dengan menggunakan modelpembelajaran kooperatif tipe STAD pada siklus I dan siklus II pada materi menceritakan kembali isi cerpen pada kegiatan tes akhir pada siklus ke II terjadi kenaikan dari rata-rata nilai 67,6 menjadi 80,1 dan untuk ketuntasan klasikal terjadi kenaikan mencapai $97 \%$. 
Berdasarkan data pencapaian hasil belajar tersebut di atas, indikator kinerja sudah tercapai artinya target $85 \%$ penguasaan minimal secara klasikal sudah terpenuhi.

Hasil kegiatan kelompok baik dari siklus I dan siklus II sama-sama memiliki penghargaan super, namun bila dianalisis, maka terjadi peningkatan dari siklus I, dimana pada siklus I perolehan rata-rata nilai 19,7 dengan penghargaan baik, dan pada siklus II dengan rata-rata nilai 29 dengan penghargaan super.

\section{Aktivitas Siswa Terhadap Model Pembelajaran kooperatif tipe STAD}

Hasil observasi yang dilakukan terhadap aktivitas siswa dilakukan pada saat pembelajaran menggunakan model pembelajaran kooperatif tipe STAD. Perbandingan aktivitas siswa disajikan pada tabel berikut:

Tabel 4.10 Perbandingan Aktivitas Siswa

\begin{tabular}{|c|c|c|}
\hline $\begin{array}{llllllll}K & e & g & i & a & t & a & n\end{array}$ & Siklus I & S i k l u s I I \\
\hline Aktivitas Siswa & 69 & 8 \\
\hline
\end{tabular}

Berdasarkan hasil observasi aktivitas siswa pada saat pembelajaran berlangsung terjadi peningkatan dari siklus I dengan rata-rata $69 \%$ meningkat pada siklus II menjadi $89 \%$. Sesuai dengan teori yang dikemukakan bahwa model pembelajaran kooperatif tipe STAD dapat meningkatkan aktivitas siswa sudah terbukti.

3. Aktivitas Guru dalam Mengelola Kegiatan Belajar dengan Pembelajaran Kooperatif TipeSTAD

Berdasarkan hasil observasi aktivitas guru pada siklus I dan siklus II dapat dilihat pada grafik di bawah ini:

Tabel 4.11 Perbandingan Aktivitas Guru Siklus I dan Siklus II

\begin{tabular}{|c|c|c|}
\hline $\mathrm{K}$ e $\mathrm{g}$ i a $\mathrm{t}$ a $\mathrm{n}$ & $\mathrm{S}$ i $\mathrm{k} 1 \mathrm{u} \mathrm{s}$ & $\mathrm{S}$ i $\mathrm{k} 1 \mathrm{u}$ s $\quad$ I I \\
\hline $\mathrm{R} a \mathrm{t} a-\mathrm{r}$ a t a & 2 & 3 \\
\hline
\end{tabular}

\section{Penutup}

\section{Simpulan}

Berdasarkan paparan data dan pembahasan hasil penelitian dalam Penelitian Tindakan Kelas (PTK) yang dilaksanakan di kelas X IIS 5 SMA Negeri 2 Banjarmasin dapat dibuat simpulan sebagai berikut:

1. Pembelajaran kooperatif tipe STAD dapat meningkatkan keterampilan berbicara siswa dari ratarata 66,6 dengan ketuntasan klasikal 60\% pada siklus I meningkat menjadi rata-rata 80,1 dengan ketuntasan klasikal 97\% pada siklus II. Hasil kerja kelompok semua mendapat penghargaan super. 
2. Aktivitas siswa mengalami peningkatan dari $69 \%$ pada siklus I mengalami peningkatan menjadi $89 \%$ pada siklus II.

3. Aktivitas guru mengalami peningkatan dari rata-rata 2,6 dengan kategori baik menjadi rata-rata 3,7 dengan kategori baik pada siklus II

\section{Saran}

Berdasarkan pembahasan dapat disarankan sebagai berikut:

1. Bagi siswa, penggunaan model pembelajaran kooperatif tipe STAD dapat menambah motivasi belajar, dan meningkatkan rasa sosialitas pada temannya, dan dapat meningkatkan hasil belajar siswa.

2. Bagi guru bahasa Indonesia di SMA, hendaknya dapat menggunakan berbagai model pembelajaran, khusus pembelajaran kooperatif tipe STAD, agar siswa tidak merasa bosan dalam mengikuti pembelajaran bahasa Indonesia.

3. Bagi kepala sekolah, hasil penelitian ini hendaknya dapat dijadikan bahan masukan guna perbaikam mutu pembelajaran di sekolah.

4. Bagi pengawas pembina, hasil penelitian ini dapat dijadikan bahan untuk mengadakan pembinaan kepada guru-guru bahasa Indonesia di SMA.

\section{Daftar Rujukan}

Arikunto, S. 2008. Penelitian Tindakan Kelas. Jakarta: PT. Bumi Aksara.

Dawud, dkk. 2004. Bahasa dan Sastra Indonesia Untuk SMA Kelas X. Yakarta: Erlangga

Depdiknas. 2006. BNSP. Jakarta: Depdiknas

Depdiknas. 2003. Undang-Undang Republik Indonesia Nomor 20 Tahun 2003 tentang Sistem Pendidikan Nasional. Jakarta: Depdiknas.

Depdiknas. 2004. KTSP SMA. Jakarta: Direktorat Jenderal Pendidikan Dasar dan Menengah.

Dimyati dan Mudjiono. 2002. Belajar dan Pembelajaran. Jakarta: Rineka Cipta

Ibrahim, Muslimin, Nur, Mohamad. 2000. Pembelajaran Koopertif. Surabaya: University Press

Kholik. 2006. Pembelajaran Matematika Dengan Pendekatan Kooperatif Model STAD di SD Negeri Waringin Kencana Wanaraya Kabupaten Barito Kuala. Banjarmasin: skripsi (Tidak dipublikasikan).

Nur, Mohamad. 2005. Pembelajaran Kooperatif. Surabaya: Pusat Sains dan Matematika Sekolah UNESA.

Sardiman. 2008. Interaksi dan Motivasi Belajar Mengajar. Jakarta: Raja Grafindo Persada. 
Subana, dan Sudrajat. 2000. Statistik Pendidikan. Bandung: Pustaka Setia

Sudjino. 2003. Pengantar Statistik Pendidikan. Jakarta: Raja Grafindo Persada.

Slavin. 2008. Cooperatifve Learning, Teori, Riset dan Praktik. Bandung: Nusa Media

Suroso. Metodik Khusus Pengajaran Bahasa Indonesia. Surakarta: Tiga Serangkai.

Tarigan, Henry Guntur. 2008. Berbicara Sebagai Suatu Keterampilan Berbahasa. Bandung: Angkasa.

Tim Instruktur. 2009. Pembelajaran Kooperatif. Jakarta: Depdiknas. 